\title{
A challenging case of anaplastic large-cell lymphoma with primary bony presentation
}

\begin{abstract}
Anaplastic large-cell lymphoma (ALCL) is a distinct type of T-cell lymphoma showing varied clinicopathological features. The clinical entities identified are systemic and primary cutaneous types. ALK+ ALCL are more common in childhood with predominant nodal presentation. Extranodal involvement is commonly seen in the skin, bones, soft tissue, lung, liver, etc., Here, we present an intriguing case of $A L K+A L C L$ in an adult patient primarily presenting as multiple bony lytic lesions.
\end{abstract}

Keywords: Anaplastic large-cell lymphoma $A L K+$, bony lytic lesions, extranodal

\section{INTRODUCTION}

Anaplastic large-cell lymphoma (ALCL) is a definite type of T-cell lymphoma showing varied clinicopathological features. The various entities identified clinically are systemic and primary cutaneous types. ALK + ALCL are more common in childhood with predominant nodal presentation. Extranodal involvement is commonly seen in the skin, bones, soft tissue, lung, liver, etc., and predominantly present as an advanced stage disease (III-IV). Patients generally have B-symptoms, especially high fever. $A L K$-negative $A L C L$ is a provisional entity in the WHO 2008 classification. ${ }^{[1]}$ The presence of ALK-NPM mutation heralds a good prognosis, hence subclassifying them into $\mathrm{ALK}+/-$ is important. Here, we present an interesting case of $A L K+\mathrm{ALCL}$ in an adult patient primarily presenting as multiple bony lytic lesions.

\section{CASE REPORT}

A 38-year-old gentleman presented to our medical oncology outpatient department with complaints of body pains for 20 days associated with right lower limb weakness. On physical examination, there were no significant findings. Complete blood picture showed hemoglobin of $153 \mathrm{~g} / \mathrm{L}$, white blood cell count of $19 \times 10^{9}$ cells/L, and platelet count of $510 \times 10^{9} / \mathrm{L}$. Peripheral smear examination

\begin{tabular}{|l|c|}
\hline \multicolumn{2}{|c|}{ Access this article online } \\
\hline \multirow{2}{*}{$\begin{array}{l}\text { Website: } \\
\text { www.asjo.in }\end{array}$} & Quick Response Code \\
\hline DOI: & \\
10.4103/ASJO.ASJO_122_16 & \\
&
\end{tabular}

showed a neutrophillic leukocytosis. No atypical cells were noted.

Biochemical investigations were ordered consisting of alpha-fetoprotein, carcinoembryonic antigen, serum light chains, protein electrophoresis, serum calcium, Vitamin D, and lactate dehydrogenase (LDH). All the results were normal except for Vitamin D and LDH levels which were $<3 \mathrm{ng} / \mathrm{ml}$ (normal $20-32 \mathrm{ng} / \mathrm{ml}$ ), and $\mathrm{LDH}$ was $588 \mathrm{U} / \mathrm{L}$ (normal 208-308 U/L).

Positron emission tomography-computed tomography (PET-CT) performed showed multifocal expansile lesion with paracortical destruction with enhancing soft-tissue component in the left parasagittal parietal bone, left humerus, bilateral multiple ribs and iliac bones, dorsolumbar vertebra, sacrum, and right femoral neck. The largest lesion in the right iliac bone showed $6.4 \mathrm{~cm} \times 4.7 \mathrm{~cm}$ lesion with soft-tissue component [Figure 1].

\section{Manasi Mundada, Faig Ahmed, A. Santa ${ }^{\mathbf{1}}$}

Departments of Laboratory Medicine and ${ }^{1}$ Medical Oncology, BIACH and RI, Hyderabad, Telangana, India

Address for correspondence: Dr. Manasi Mundada, Jailakshmi Towers, Musheerabad, Hyderabad - 500 080, Telangana, India. E-mail: manasicmundada@gmail.com 


\section{MATERIALS AND METHODS}

Tru-cut biopsy was processed; $\mathrm{H}$ and E staining, immunohistochemistry (IHC), and fluorescent in situ hybridization (FISH) were done.

\section{RESULTS}

Tru-cut needle biopsy from the right iliac bone was performed, which revealed sheets of large plasmacytoid cells, having eccentric hyperchromatic nuclei with scattered cells with horseshoe nuclear configuration conspicuous nucleoli at places. Cytoplasm was moderate in amount and eosinophilic [Figure 2a and b].

IHC revealed neoplastic cells to be negative for pan cytokeratin, CD20, CD3, CD5, CD15, CD138, HMB45, SALL4, and CD1a. The neoplastic cells showed positivity for epithelial membrane antigen (EMA), faint LCA positive [Figure 3a and b]. IHC for CD30 showed diffuse strong membranous positivity and ALK 1 was faint positive [Figure $4 \mathrm{a}$ and $\mathrm{b}$ ]. FISH performed elsewhere and was positive for the translocation involving chromosome 2 in $80 \%$ of the cells studied [Figure 5].

Bone marrow aspiration and biopsy performed as part of staging revealed a diluted aspirate with scattered large

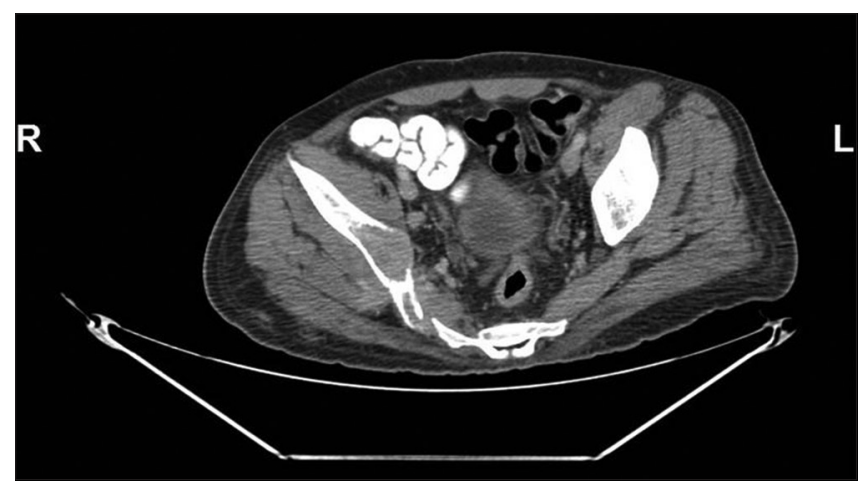

Figure 1: Computed tomography scan image in the bone window shows a lytic lesion in the right iliac bone from where biopsy was done

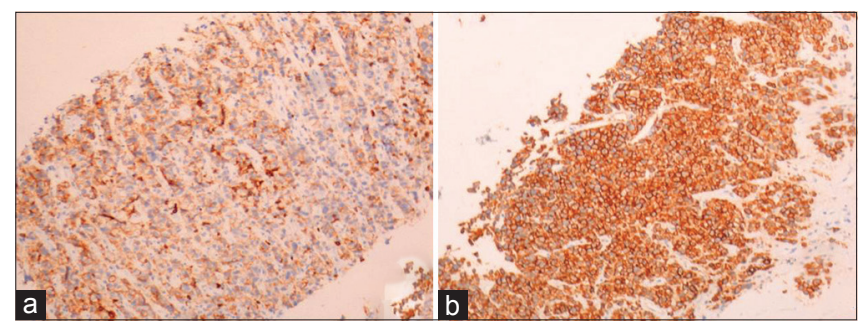

Figure 3: (a) Faint leukocyte common antigen positive in neoplastic cells. $(100 \mathrm{X})(\mathrm{b})$ Epithelial membrane antigen strong membranous positive in neoplastic cells (100X) atypical cells, highly suspicious of involvement by disease. However, trephine biopsy was unremarkable.

\section{DISCUSSION}

Primary lymphoma of the bone constitutes only $5 \%$ of the malignant tumors of the bone. ${ }^{[1]}$ The most common subtype being diffuse large B-cell lymphoma. ALCL was first described by Stein et al. in 1985 by their peculiar morphological features and consistent presence of CD30 in all the cases. ${ }^{[2]} \mathrm{ALK}$-positive ALCL represents only $3 \%$ of adult non-Hodgkin's lymphoma, ${ }^{[3]}$ and most common presentation is as nodal disease. In the present case, the patient presented with body pains. PET-CT finding of multiple expansile lytic lesions with age in consideration prompted the clinical differentials of metastasis from germ cell tumor versus a multiple myeloma. However, the workup for both of these differential diagnosis came negative. The extensive bony involvement without extranodal disease warrants differential diagnosis of round cell tumors, Ewing's/ primitive neuroectodermal tumor, Langerhans cell histiocytosis, metastatic Germ cell tumor, and Hodgkin lymphoma ${ }^{[4]}$ in children and metastatic tumor or multiple myeloma in adult. ${ }^{|5|}$

Various morphological subtypes of $A L K+$ ALCL are described in literature ${ }^{[3]}$ like the common type composed of large pleomorphic "hallmark cells" having large vesicular kidney-shaped nucleus with abundant eosinophilic cytoplasm. The other major morphological patterns described are lymphohistiocytic, small-cell variant, and Hodgkin-like pattern. ${ }^{[2,6]}$ The present case showed common type of morphology.

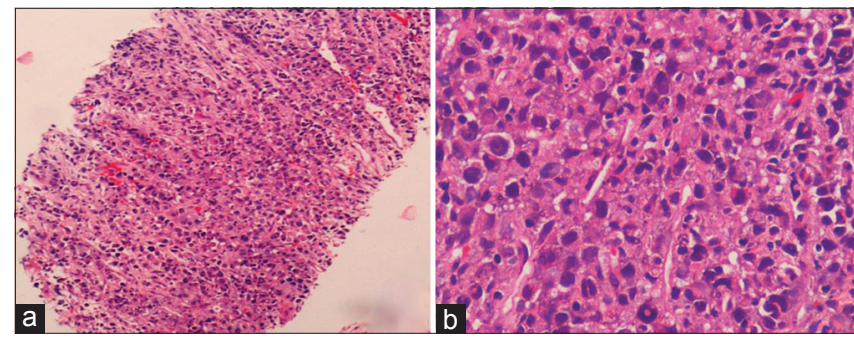

Figure 2: (a) Tru-cut biopsy from the iliac lesion showing sheets of cells. $(100 \mathrm{X})(\mathrm{b})$ The cells are large and show round to indented nucleus, perinuclear hoff, and moderate amount of eosinophilic cytoplasm ( $H$ and $E$, 400X)

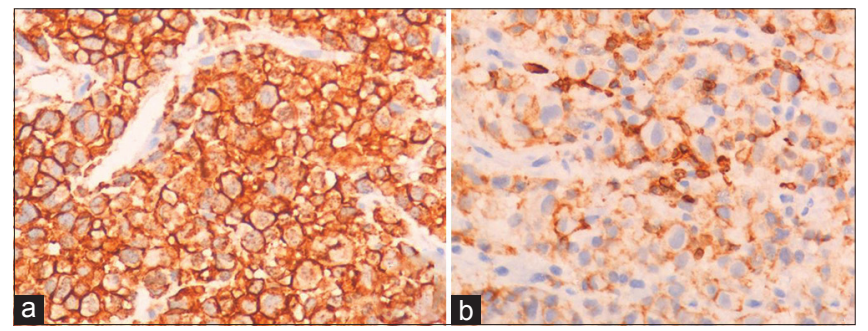

Figure 4: (a) CD30 shows strong membranous staining. (400X) (b) ALK positive in neoplastic cells (400X) 


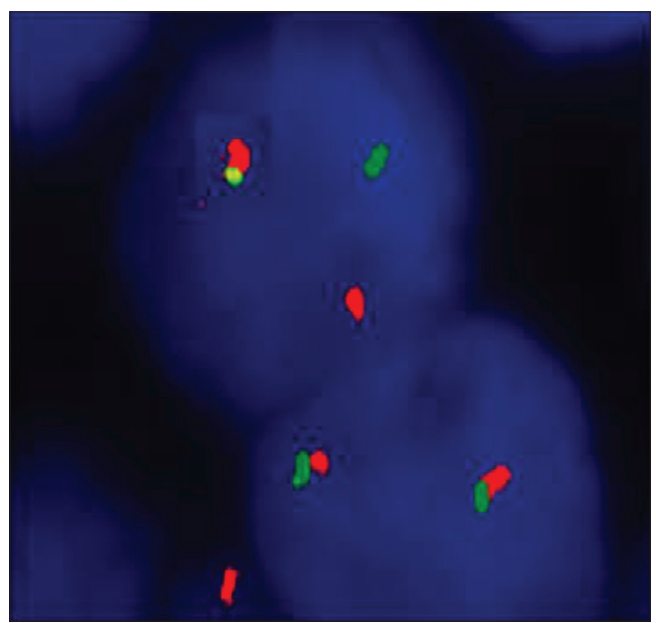

Figure 5: Vysis LSI Alk Dual Color Break Apart probe, the upper cell in the image is positive for the Alk 1 mutation

The immunophenotype of these cells show strong expression of CD30, which is the most consistent marker to clinch the diagnosis. ALK and EMA show heterogeneous expression. T-cell markers such as CD3, CD5, CD2, and CD4 are variably expressed. In some instances, loss of T-cell markers is seen, null phenotype. ${ }^{\left[{ }^{[7]}\right.}$ Commonly, loss of CD3 is seen in $75 \%$ of the cases. ${ }^{[3]}$ In the present case, $\mathrm{CD} 30$ showed strong membrane positivity. EMA and ALK were positive; however, CD3 was negative, and other T-cell markers could not be done due to nonavailability.

Bone marrow involvement is seen in $10 \%$ of the cases, and sensitivity of picking up involvement improves to $30 \%$ with the use of IHC. The pattern of involvement pathognomonic for ALCL is along the lymphatic sinusoids. ${ }^{[6]}$ In the present case, scattered atypical cell was noted in the bone marrow aspirate and imprints; however, biopsy was inconclusive for involvement.IHC with CD30 antibody was performed on trephine biopsy to rule out involvement by the disease was negative for presence of disease.

The molecular translocation 2,5 gives rise to NPM1-ALK chimeric fusion gene which is responsible for activating tyrosine kinase pathway leading to oncogenesis. ${ }^{[7]}$ Translocation 2,5 is seen in $80 \%$ of the cases with IHC staining seen in both cytoplasm and membrane of the large cells. ${ }^{[8]}$

The variant translocation leads to translocation of $A L K$ gene to other chromosomes such as $1,2,3,17,19,22$, and $\mathrm{X}^{[8]}$

\section{Treatment}

The patient was started on Cyclophosphamide, Hydroxyduanorubicin, Oncovin Prednisone-based chemotherapy. There was a partial response to the treatment with decrease in the size of lesion in the liver, L4 vertebra, left parietal bone, and iliac crest. However, few new lesions were found in mediastinum, and abdominal nodes and lesions in the right iliac bone and femoral bone showed the progression of disease. The patient succumbed to the disease after 4 cycles of chemotherapy. ALK positivity in ALCL gives a good prognostic connotation; however, the presence of $A L K$ does not give a prognostic value in primary bone ALCL. ${ }^{[9]}$

\section{Take-home message}

$\mathrm{A} L K+\mathrm{ALCL}$ has varied clinical and morphological picture with which this disease can present; the importance of using immunohistochemical stains judiciously with congruent use of molecular techniques in clinically and histologically suspicious cases cannot be overemphasized.

\section{Declaration of patient consent}

The authors certify that they have obtained all appropriate patient consent forms. In the form the patient(s) has/have given his/her/their consent for his/her/their images and other clinical information to be reported in the journal. The patients understand that their names and initials will not be published and due efforts will be made to conceal their identity, but anonymity cannot be guaranteed.

\section{Financial support and sponsorship}

Nil.

\section{Conflicts of interest}

There are no conflicts of interest.

\section{REFERENCES}

1. Bakshi NA, Ross CW, Finn WG, Valdez R, Ruiz R, Koujok K, et al. ALK-positive anaplastic large cell lymphoma with primary bone involvement in children. Am J Clin Pathol 2006;125:57-63.

2. Falini B. Anaplastic large cell lymphoma: Pathological, molecular and clinical features. Review. Br J Haematol 2001;114:741-603.

3. Delsol G, Falini B, Muller-Hermelink HK, Campo E,Jaffe ES, Gascoyne RD et al. Anaplastic large cell lymphoma ALK-positive. In Swerdlow SH, editor. WHO Classification of Hematopoetic and Lymphoid Tissue. $4^{\text {th }}$ ed. Lyon: IARC; 2008. p. 312-6.

4. Mandujano-Alvarez GJ, Moreno-Sánchez F, Morales-Polanco M, García-Ortiz JR, Ortiz-Hidalgo C. Primary bone anaplastic large cell lymphoma. Acta Ortop Mex 2009;23:142-8.

5. Barley K, Harris JA, Diefenbach C, Jagannath S, Chari A. Misdiagnosis of non-Hodgkin lymphoma as multiple myeloma. J Clin Oncol 2012;30:e364-7.

6. Inghirami G, Pileri SA, European T-Cell Lymphoma Study Group. Anaplastic large-cell lymphoma. Semin Diagn Pathol 2011;28:190-201.

7. Jacobsen E. Anaplastic large-cell lymphoma, T-/null-cell type. Oncologist 2006;11:831-40.

8. Ferreri AJ, Govi S, Pileri SA, Savage KJ. Anaplastic large cell lymphoma, ALK-positive. Crit Rev Oncol Hematol 2012;83:293-302.

9. Nagasaka T, Nakamura S, Medeiros LJ, Juco J, Lai R. Anaplastic large cell lymphomas presented as bone lesions: A clinicopathologic study of six cases and review of the literature. Mod Pathol 2000;13:1143-9. 